\title{
A LIAISON EM LÍNGUA FRANCESA: FALANTES DE FLE VS FALANTES NATIVOS DE FRANCÊS
}

\author{
LIAISON IN FRENCH: \\ FRENCH FOREIGN LANGUAGE SPEAKERS VS FRENCH NATIVE SPEAKERS
}

Vanessa Gonzaga Nunes

Mestranda do Programa de Pós-graduação em Linguística - UFSC

\begin{abstract}
Resumo
O objetivo do presente estudo é observar o fenômeno fonológico do francês, chamado liaison. Para isso, gravaram-se dados de fala de dois nativos do francês e de quatro aprendizes de francês língua estrangeira (FLE), nativos do português brasileiro. Os dados de nativos e aprendizes foram analisados acusticamente, observando-se as fronteiras de palavras, ou seja, as regiões que pudessem revelar a ocorrência de liaisons obrigatórias, facultativas e proibidas. Essas análises se propõem a responder: (a) locutores nativos do francês considerado standard e aprendizes do FLE realizam todas as liaisons obrigatórias? (b) como esses locutores realizam as liaisons facultativas? (c) em relação aos contextos em que há proibição de realização de liaisons, como os nativos e os aprendizes se comportam? (d) existem outros contextos, não considerados pelas regras gramaticais da língua francesa em que esses falantes nativos e aprendizes realizam liaisons? Em caso afirmativo, essas "falsas liaisons" provocam fenômenos fonéticos/fonológicos, como apagamentos ou ressilabação?
\end{abstract}

Palavras-chave: Liaison, língua francesa, aprendizes de FLE.

\begin{abstract}
The aim of this work was to study liaison, a phonological phenomenon of French. Two reports were recorded by four native French journalists and by four students of French Foreign Language (FLE), Brazilian Portuguese native speakers. Native and learners readings were analyzed in order to observe word boundaries which could reveal mandatory, optional and prohibited liaisons. These analyzes aimed to answer the following questions: (a) Do native speakers of standard French and FLE learners perform all mandatory liaisons? (b) How are optional liaisons carried out? (c) Regarding to prohibited liaisons contexts, how do natives and learners behave? (d) Are there contexts not considered by French grammar rules in which native and learners speakers carry out liaisons? If affirmative, do these "false liaison" cause phonetic/phonological phenomenon, such as deletion or resyllabification?
\end{abstract}

Keywords: Liaison, French, FLE learners. 


\section{INTRODUÇÃO}

O presente artigo se propõe a examinar a liaison $^{1}$ na língua francesa, um fenômeno fonético cuja realização ou não pode trazer implicações no nível da compreensão. A gramática da língua francesa estabelece contextos em que a liaison é obrigatória, outros nos quais ela é facultativa e ainda aqueles em que tal fenômeno é proibido. A experiência de sala de aula tem nos mostrado que, em um primeiro momento, alunos iniciantes ignoram totalmente a possibilidade de produzir liaison e, em um segundo momento, juntam indiscriminadamente todas as consoantes latentes às vogais subsequentes. Para os níveis mais avançados, a exigência pela "boa" pronúncia cresce assim como cresce a cobrança pela realização das liaisons obrigatórias, o incentivo pela produção das facultativas e a inquietação diante das proibidas. Dessa experiência, surgiu o interesse em verificar como os aprendizes de francês realizam tal fenômeno e em que momento se apropriam de maneira significativa das regras.

A pronúncia dos aprendizes está, todo tempo, sendo comparada à produção dos nativos, mesmo que não tenhamos muita clareza de como os nativos realizam efetivamente determinado fenômeno. Parece, então, fundamental verificar como a liaison é realizada por aprendizes de francês língua estrangeira (doravante FLE), mas também analisar mais detidamente a produção de locutores nativos de francês, para que possamos observar quais as semelhanças e distinções entre essas produções.

Logo, este artigo se propõe a responder as seguintes questões:

(a) locutores nativos do francês considerado standard e aprendizes do FLE realizam todas as liaisons obrigatórias?

(b) como esses locutores realizam as liaisons facultativas?

(c) em relação aos contextos em que há proibição de realização de liaisons, como os nativos e os aprendizes se comportam?

(d) Existem outros contextos, não considerados pelas regras gramaticais da língua francesa em que esses falantes nativos e aprendizes realizam liaisons? Em caso afirmativo, essas "falsas liaisons" provocam fenômenos fonéticos/fonológicos, como apagamentos ou ressilabação?

Inicia-se esta discussão com a apresentação, na Seção 2, do tema, a partir de um breve histórico do uso da liaison; seguido de um levantamento dos tipos considerados pela Gramática Normativa; sua problemática para aprendizes de FLE e as regras que nortearão as análises dos dados - observando classificações existentes. Na Seção 3, apresentam-se a metodologia de análise dos dados e os corpora investigados. Na Seção 4, apresentam-se as análises e discussões dos dados que dizem respeito tanto a aprendizes do FLE quanto aos nativos do francês. E, finalmente, na Seção 5, serão apresentadas as respostas às questões aqui levantadas.

\footnotetext{
${ }^{1}$ Será utilizado o termo em francês por estar se tratando do fenômeno nessa língua.
} 


\section{A LIAISON}

O que é a liaison na língua francesa? A liaison, foco deste estudo, é um tipo de sandhi externo, um fenômeno da língua francesa que acontece em fronteira de palavras e acaba modificando a pronúncia de um enunciado e influenciando a estrutura da cadeia da fala.

A liaison, segundo Dugua \& Chabanal (2006), é um fenômeno de alternância fonológica que se atualiza entre duas palavras (palavra 1 e palavra 2) pelo aparecimento de uma consoante de ligação, cuja natureza é determinada pelo tipo de palavra 1 .

Portanto a liaison tem sua origem no enfraquecimento progressivo das consoantes finais desde o francês antigo, diante de vogal e se aplicando irregularmente segundo o contexto léxico-sintático e sociolinguístico (THOMAS, 1998).

Um estudo de Boë et Tubach (1992 apud CHEVROT et al., 2005) sobre 20 horas de fala adulta mostra que /n/, /z/ e /t/ representam 99,7\% das liaisons realizadas, as demais ocorrências estão distribuídas entre $/ \mathrm{p} /, / \mathrm{r} / \mathrm{e} / \mathrm{d} /$. Essas liaisons são, na maior parte do tempo, classificadas como: (i) liaison obrigatória; (ii) liaison facultativa, ou seja, possíveis, mas não sistematicamente realizadas; (iii) liaison proibida.

A liaison entre o fonema latente em posição final e uma vogal em posição inicial provoca a ressilabação, isto é, a consoante final de uma palavra - que não era pronunciada quando a palavra se apresentava de maneira individual - aparece e se junta à vogal inicial da palavra seguinte criando uma nova sílaba. Essa nova organização silábica representa um fenômeno gramatical que leva em consideração as dimensões fonológicas, morfológicas, sintáticas ou semântico-enunciativas da língua francesa.

Grosso modo, pode-se dizer que, quando uma palavra termina por uma consoante escrita, mas não pronunciada, essa pode ligar-se a uma vogal que inicia a palavra seguinte, formando então uma sílaba. A esse fenômeno chamamos liaison e pode-se dizer que o aparecimento de consoantes latentes sugere uma forma de regularização morfológica.

\subsection{A liaison, sua história e seu uso}

Há mais de 40 anos, a liaison é considerada um dos fenômenos vedetes da fonologia do francês (TRANEL, 2000 apud CHEVROT et al, 2005). Segundo Thomas (1998), a liaison é um fenômeno que toca os aprendizes do FLE, e que os erros cometidos por realizações inadequadas impõem graves problemas a esses aprendizes. $\mathrm{O}$ autor afirma que tal fenômeno é aprendido por osmose, o que é relativamente fácil no meio francófono, mas problemático no contexto das nossas universidades, onde a falta de ambientes em que se possa falar somente em francês nos obriga a procurar ensinar tendências ou regras.

Para entender melhor o uso da liaison nos dias atuais, é preciso olhar através dos séculos os rastros desse fenômeno na língua francesa. Nos séculos XI e XII, nasce uma grafia simplificada e pode-se dizer que, em um período do antigo francês, quase todas 
as consoantes escritas eram pronunciadas. (PLOUZEAU ${ }^{2}$ ). A partir do século XII, as consoantes finais passam a não ser mais pronunciadas, mas a realização de uma consoante de ligação entre duas palavras marca os resquícios de um francês antigo, evitando assim o agrupamento de duas vogais ( mes ['me] - amis ['ami] $\rightarrow$ [me. 'za. mi]) e marcando uma relação sintática muito estreita entre essas duas palavras de contato.

Vamos encontrar ainda em um canto e outro da literatura uma pincelada que pode explicar realizações particulares. Nos manuscritos medievais, por exemplo, encontramos pistas que podem desvendar os motivos de termos liaisons que deveriam se realizar a partir de uma consoante latente [d], mas que se efetiva com a realização de um [t], como em quand elle. Esses manuscritos apresentam o vocábulo grand, escrito grant, nome que servia na época para qualificar tanto o gênero masculino quanto o feminino. Já que a grafia dessa época correspondia, em geral, à sua pronúncia, nesse caso, portanto, a palavra grant contemplava um [t] audível.

Observando a língua francesa falada na atualidade, ou seja, no início do século XXI, é incontestável a verificação de que a língua sempre se moveu e continua a se mover. Os gramáticos, desde sempre, tentam registrá-la, classificá-la, descrever as regras de funcionamento e tentam também estabelecer um modelo standard, uma referência do seu "bom uso".

A liaison não está fora desse desenho do que se considera como modelo de língua falada. Pierret (1994) abre seu capítulo sobre a liaison ${ }^{3}$ dizendo que é preciso lembrar que a liaison é sobretudo uma questão de "nível de língua": a língua corrente faz menos liaison que a língua soignée $e^{4}$ e bem menos ainda que a língua poética que representa um uso arcaico. Vejamos alguns exemplos citados por Pierret (1994) que ilustram a noção do nível da língua ou registro, conforme sugere o autor:

(1) des[z]_hommes[ø][/illustres[ø]/ont[ø]/attendu (familiar: somente a liaison obrigatória composta de artigo + substantivo é realizada)

(2) des[z]_hommes[ø]/illustres[ø]/ont_attendu (língua corrente, mais formal: a liaison é realizada entre o artigo e o substantivo e entre o verbo auxiliar e o principal)

(3) des[z]_hommes[z]_illustres/ont_attendu (língua muito formal, por exemplo em uma conferência: agora tem-se a liaison realizada entre o artigo e o substantivo; o substantivo e o adjetivo e entre o verbo auxiliar e o principal)

(4) des_hommes_illustres_ont_attendu (recitando versos clássicos: nesse caso, em todos os contextos em que a palavra anterior finaliza por consoante e a seguinte inicia por vogal foram realizados com liaison (pronúncia arcaica))

\footnotetext{
2 May Plouzeau, é professor da Universidade de Provence e participa do Laboratoire de Français Ancien. O laboratório virtual pode ser acessado em http://www.uottawa.ca/academic/arts/lfa/. Último acesso em 17 de outubro de 2009.

${ }^{3}$ Pierret, J. M. Phonétique historique du français et notions de phonétique générale, 1994.

${ }^{4}$ Língua formal é uma possível tradução para langue soignée.
} 
Outros autores, no entanto, irão atribuir e justificar o uso da liaison por outros vieses. Thomas (1998), por exemplo, observa que a produção depende do contexto fonético e gramatical, da frequência do emprego, do nível da língua, da produção inicial, da situação e mesmo do indivíduo (quadro social e preferência individual). Ele adverte que a evolução da pronúncia do francês desde suas origens latinas se caracteriza primeiramente pela erosão gradual que se efetua inegavelmente sobre os diferentes pontos do sistema, notadamente, sobre as consoantes finais que apresentam um enfraquecimento. $\mathrm{O}$ autor apresenta as possibilidades de produção: (1) manutenção da consoante (une vi[s]), (2) alteração parcial (neu[f] / neu[v] ans), (3) alteração e queda parcial (plu[s], plu[z] aride, plu[ø] fort), (4) queda parcial (le[z] amis / le [ø] chiens), et (5) queda total (chat, cha [ø]).

Mas até que ponto essa evolução influencia no processo de ensino aprendizagem do francês? Estamos falando de consoantes que ora aparecem, ora não aparecem, ora transformam pronúncias que muitas vezes não são descritas por nenhuma regra. Estudos indicam que os aprendizes do francês podem ter dificuldades com as diferenças entre a grafia e a pronúncia. Yersin-Besson et Grosjean (1996 apud STRIDEFELT, 2005) estudaram a influencia da liaison sobre o reconhecimento das palavras. Um teste de detecção de palavras realizado com nativos mostrou que a liaison retarda $o$ reconhecimento das palavras.

Vários autores escreveram sobre esse fenômeno fonético, no intuito de descrevê-lo ou de analisá-lo, segundo as possibilidades de realização. Observa-se que os autores, principalmente os mais recentes ${ }^{5}$, avançam seus estudos no intuito de mostrar que a heterogeneidade e a diversidade são os fatores que mais condicionam a realização efetiva das liaisons.

\subsection{A liaison entre nativos e estrangeiros}

Segundo Wioland e Pagel (1991), a liaison tem historicamente sua origem na estrutura da sílaba. Carton (1974 apud ROSSI 1998) afirma que a liaison é um caso particular de enchaînement ${ }^{6}$. Os mecanismos que organizam a estrutura da sílaba são complexos, e a reestruturação de acordo com Chevrot et al. (2007) não é inata, mas uma questão de exposição ao uso da língua.

Estudos afirmam que crianças nativas do francês, em período de aquisição da língua materna, têm dificuldade de dominar o processo de ressilabação que dá origem à liaison uma vez que nesta fase, elas não são capazes de administrar o processo de segmentação e formação de sintagmas. Chevrot et al. (2007), examinando a aquisição das liaisons pelas crianças nativas do francês, verificaram que elas utilizam suas próprias estratégias de segmentação do oral (faz-se importante lembrar aqui que, na fase de aquisição da língua, as crianças não são influenciadas pela escrita). Sintagmas do tipo l'ours, são

\footnotetext{
${ }^{5}$ Laks (2003, 2005), Pagliano e Laks (2005), dentre outros.

${ }^{6}$ Traduzida aqui como encadeamento: uma consoante de encadeamento é sempre pronunciada no final de uma palavra, mesmo se ela é isolada. Se a palavra começa por vogal pronunciada, a consoante final da palavra precedente se torna a consoante inicial da palavra que segue. A consoante de encadeamento não muda nunca a sua natureza fonética.
} 
frequentemente pronunciados por crianças como [l'nuRs], ou ainda deux ours poderá ser facilmente entendido por [dø'nuRs] ou [dø'uRs]. Mas de onde viriam essas inserções? O que acontece é que a criança está diariamente exposta a sintagmas do tipo: un ours, em que se faz a liaison em [n]. Notamos então que esse [n] que faz liaison na linguagem infantil é herança de uma referência muito presente como modelo.

Assim as crianças com idades entre 2 e 6 anos produzem ao longo de uma seção de gravação a palavra 2 nas formas [lurs], [nurs], [zurs], [turs], [urs] depois do adjetivo petit (por influência das referências l'ours; un ours; deux ours; petit ours e ours). A criança poderia dispor às vezes de cinco alomorfes no seu léxico interno, mas não chegaria a ligar imediatamente com a palavra 1, o que explicaria as ativações (CHABANAL, 2003). Para as crianças nativas, a evolução concernente às liaisons facultativas e obrigatórias acontece de maneira distinta. Certos estudos mostram que crianças com idade entre 10 e 11 anos realizam $12 \%$ das liaisons facultativas, enquanto os adultos "cultos" atingem 79\% das realizações em situação formal (AHMAD, 1993 apud CHEVROT et al. 2007).

Já o adulto apresenta domínio no processo de montagem das peças. $\mathrm{O}$ adulto realiza o fonema [z] entre "les" e "avocats", ocasionando naturalmente a ressilabação: [lE 'za vo $\mathrm{kA}$ ], o que não acontecerá com "les sacs", pois o [s] não terá assimilação de vozeamento e a produção se dará no nível fonológico como [1E'sak], por exemplo.

Pagliano e Laks (2005) afirmam que o sexo do locutor não influencia na realização de liaisons, mas a idade pode sim ser um fator importante. Esses autores concluíram que a liaison realizada por nativos parece apresentar tendência em aumentar com a idade, mas afirmam também que é preciso ter cuidado com essa informação. $\mathrm{Na}$ verdade, com a idade, a inserção social e profissional evolui e o rendimento também se eleva. As trajetórias sociais são índices de modificação de posicionamento no espaço social sincrônico. Então, não se trata mais de variação diacrônica de uma geração à outra, mas de uma variação puramente social.

Estudos realizados ${ }^{7}$ com estrangeiros, mesmo com aprendizes em nível avançado, demonstram que os percentuais de realização de liaison facultativa são relativamente inferiores àqueles dos locutores nativos. Esses últimos sobre empregam as variantes formais, mesmo em situações nas quais as variantes informais seriam socialmente mais apropriadas. Howard (2005) acrescenta ainda que suas pesquisas junto a aprendizes de FLE revelam taxas de emprego de liaison muito pouco elevadas entre um adjetivo e um substantivo, e após um pronome objeto; e que um dos seus grupos de aprendizes pesquisados simplesmente ignorou o emprego das liaisons facultativas em um grande número de contextos sintáticos.

Laks (2005) mostra que a liaison pode ser possível no interior de uma palavra fonológica e proibida entre duas palavras fonológicas, ou seja, pode-se ter, em um mesmo contexto segmental, uma liaison que pode ser obrigatória, possível ou proibida. A literatura não se ocupa muito de analisar profundamente a liaison proibida no falar dos nativos, talvez porque julgue que esse tipo de liaison não imponha problemas

\footnotetext{
${ }^{7}$ Por exemplo, Howard (2005) e Mougeon, Nadasdi e Rehner (2003)
} 
relevantes aos nativos. Entretanto, os aprendizes apresentam uma preocupação em fazer uso das regras e possivelmente, no anseio da realização, findam por errar, como por hipercorreção.

Para as análises que serão realizadas por este estudo, levaremos em conta a classificação dos tipos de liaison apresentadas em Dellatre (1951 apud PAGLIANO e LAKS, 2005), Léon (1966) e Malmberg (1976) (apud ROSSI, 1998), que atualmente ainda é incorporada pelas Gramáticas Normativas do francês standart. Para esses autores, as liaisons podem ser classificadas conforme exposto nos Quadros 1 e 2.

QUADRO 1. Contextos de liaison obrigatória e facultativa apresentados em Delattre (1951 apud PAGLIANO e LAKS, 2005)

\begin{tabular}{|l|l|l|l|}
\hline \multicolumn{2}{|c|}{ Liaison Obrigatória } & \multicolumn{2}{c|}{ Liaison facultativa } \\
\hline artigo+ + & les_enfants, aux_amis & nome plural + & plats_exquis \\
\hline adjetivo + & ces_amis, deux_amis & pronome num. pessoal + & Plusieurs_écoutent \\
\hline pronome pessoal + & vous_y êtes, nous_en & pronome pessoal posterior + & Amusons-nous_un peu \\
\hline verbo+ pronome pessoal & Allez_y, vient_elle & verbo + & suis_emberbe \\
\hline verbo (impessoal) + & c'est_évident & preposição + & depuis_un an \\
\hline preposição + & $\begin{array}{l}\text { Dans_un an, } \\
\text { en_hiver }\end{array}$ & advérbio polissilábico & jamais_àl'heure \\
\hline advérbio monossilábico+ + & très_utile & conjunção monossilábica & mais_alors \\
\hline & & X + invariável & maison_et, bons_ou \\
\hline
\end{tabular}

QUADRO 2. Contextos de liaison proibida apresentados em Léon (1966 apud ROSSI, 1998) e Malmberg (1976 apud ROSSI, 1998)

\begin{tabular}{|c|c|}
\hline \multicolumn{2}{|c|}{ Liaison Proibida } \\
\hline não há “liaison" entre dois grupos rítmicos & Alors/ il arrive \\
\hline $\begin{array}{l}\text { depois dos pronomes "ils" e "elles" em interrogações } \\
\text { com inversão }\end{array}$ & Vont-ils/arriver? \\
\hline depois da conjunção " et" & Il va et/ il vient, Jean et/Marie \\
\hline verbo + verbo no infinitvo & Il doit être \\
\hline substantivo + substantivo & Albert /Amiel, mon cousin/Adolphe \\
\hline entre um substantivo (ou adjetivo) e uma preposição & Un moulin/à vent, des sacs à vendre \\
\hline entre um substantivo e um adjetivo no singular ${ }^{8}$ & Un enfant/adorable \\
\hline entre dois adjetivos (ou particípios) ${ }^{9}$ & Des vins rouges/italiens \\
\hline pronomes relativos + & Les livres auxquels/il pense \\
\hline${ }^{10}$ negação com rien + & Il n'y a rien/ici \\
\hline${ }^{11}$ negação com nom+ & Un livre non/achevé \\
\hline com palavras que podem ser isoladas & Il dit/oui, mais/oui \\
\hline com certos números ${ }^{12}$ & les /huit jours; les/huitièmes de finale \\
\hline para distinguir do plural & Enfant/adorable - enfants_adorables \\
\hline para distinguir um substantivo de um adjetivo & $\begin{array}{l}\text { savant/aveugle (subst }+ \text { adj) } \\
\text { savant_aveugle (adj+subst) }\end{array}$ \\
\hline expressões fechadas & $\begin{array}{l}/ \mathrm{z} / \text { - nez/ à nez } \\
/ t / \text { - de part/ en part } \\
/ n / \text { - bon/ à rien }\end{array}$ \\
\hline Diante do $h$ aspirado & les/ héros \\
\hline
\end{tabular}

\footnotetext{
${ }^{8}$ no plural, a liaison pode ser facultativa: des enfants_adorables

${ }^{9}$ mas: há liaison em un portail grand_ouvert

${ }^{10}$ mas: há liaison em rien_à faire ou rien_à voir

${ }^{11}$ mas: há liaison em non activité

${ }^{12}$ mas: há liaison em dix-huit, vingt-huit. Pode-se dizer : les/onze ou il est_onze heure
} 
A partir dos dados até aqui apresentados, passamos à metodologia de coleta dos dados e a sua respectiva análise.

\section{METODOLOGIA}

\subsection{Os corpora e os participantes}

Para que se pudesse avaliar o comportamento das liaisons na língua francesa, foram gravadas duas reportagens jornalísticas, produzidas por falantes nativos. Escolheu-se esse tipo de produção, uma vez que as matérias jornalísticas são consideradas uma referência do francês standard.

1. A reportagem Le séquençage du génome du panda foi divulgada no mês de fevereiro de 2009 no site http ://www.cite-sciences.fr e no mês de abril no site http://www.tv5.org. Essa reportagem contou com a participação de 4 falantes nativos do francês do sexo masculino. Analisaram-se ao todo 57 contextos passíveis de apresentarem qualquer tipo liaison.

2. A reportagem Partenaire de l'année de la France au Brésil du 21 avril au 15 novembre 2009 foi divulgada no mês de abril de 2009 no site http://www.tv5.org. Essa reportagem contou com a participação de 3 falantes nativos do francês, do sexo masculino. Analisaram-se 23 contextos passíveis de apresentarem qualquer tipo de liaison.

Essas reportagens jornalísticas foram transcritas ortograficamente e foram lidas em voz alta por um grupo de 4 falantes brasileiros, do sexo masculino, com idade entre 20 e 40 anos, cuja língua materna é o português do Brasil. Esses falantes brasileiros são aprendizes de FLE na Universidade Federal da Santa Catarina. Dois aprendizes são considerados de nível intermediário, ou seja, $3^{\circ}$ e $4^{\circ}$ semestres; um de nível avançado, isto é, $5^{\circ}$ semestre; e um de nível debutante, ou seja, do $2^{\circ}$ semestre. Eles são identificados pelos códigos: A para o aprendiz de nível debutante, $\mathbf{B}$ e $\mathbf{C}$ para os aprendizes de nível intermediário e $\mathbf{D}$ para o aprendiz de $5^{\circ}$ semestre.

Foram encontrados 83 contextos passíveis de liaisons nas reportagens gravadas e lidas. A partir dessas gravações, analisaram-se as produções de nativos do francês e de aprendizes do FLE, selecionaram-se e etiquetaram-se todas as fronteiras interpalavras passíveis de liaison a partir de uma classificação prévia das palavras envolvidas.

Os corpora foram analisados acusticamente e a gravação e a etiquetagem foram efetuadas com o auxílio do software PRAAT ${ }^{13}$. A frequência de amostragem selecionada foi de $22 \mathrm{kHz}$, suficiente para as análises aqui efetuadas. Após ter verificado os dados dos nativos e dos aprendizes de FLE, compararam-se as produções. Os resultados dessas análises são apresentados a seguir.

\footnotetext{
13 Praat é um programa de análise de fala, versão 5.1.02, disponível livremente a partir do site www.praat.org; desenvolvido por Paul Boersma e David Weenink; copyright (C) 1992-2006.
} 


\section{AS ANÁLISES}

Com o objetivo de contribuir com esses estudos, espera-se explorar os corpora, analisando e comparando os dados aqui apresentados. Os dois documentos pesquisados totalizam 83 contextos que podem permitir a liaison; desses $69,88 \%$ dos contextos são convenientes a liaisons obrigatórias, $19,28 \%$ a liaisons facultativas e 10,84\%, a proibidas. Esses dados são os mesmos para os aprendizes de FLE.

\subsection{Locutores Nativos}

Melhor detalhando os dados relacionados aos falantes nativos do francês, observamos que o corpus 1, correspondente à reportagem Le séquençage du génome du panda, apresentou :

(i) 41 contextos de liaison obrigatória;

(ii) 11 contextos de liaison facultativa;

(iii) 08 contextos de liaison proibida.

Esses falantes nativos realizaram 37 liaisons obrigatórias, 7 liaisons facultativas e nenhuma liaison considerada proibida. Ou seja, eles realizaram $90 \%$ das liaisons obrigatórias; $63,6 \%$ das liaisons facultativas e não realizaram as proibidas.

Já para o corpus 2, correspondente à reportagem Partenaire de l'année de la France au Brésil du 21 avril au 15 novembre 2009, temos :

(i) 17 contextos de liaison obrigatória;

(ii) 05 contextos de liaison facultativa;

(iii) 01 contextos de liaison proibida.

Nesse caso, os falantes nativos realizaram 15 liaisons obrigatórias, 03 liaisons facultativas e 01 liaison considerada proibida, o que representa a realização de $88,2 \%$ das liaisons obrigatórias, $60 \%$ das liaisons facultativas e 100\% das liaisons proibidas.

Considerando todos os casos de liaison, temos, na Tabela 1, um panorama dos resultados obtidos pelos nativos do francês. Por essa tabela, podemos dizer que, conforme esperado, na fala mais cuidada (standart), há prevalência do uso das liaisons obrigatórias $(89,6 \%)$, as facultativas são preferencialmente realizadas $(66,5 \%)$ e as proibidas evitadas $(89 \%)$.

TABELA 1. Liaisons realizadas por locutores nativos do francês

\begin{tabular}{|c|cc|cc|cc|}
\hline & \multicolumn{2}{|c|}{$\begin{array}{c}\text { Liaisons } \\
\text { Obrigatórias }\end{array}$} & \multicolumn{2}{c|}{$\begin{array}{c}\text { Liaisons } \\
\text { Facultativas }\end{array}$} & \multicolumn{2}{c|}{$\begin{array}{c}\text { Liaisons } \\
\text { Proibidas }\end{array}$} \\
\hline Contexto & \multicolumn{2}{|c|}{58} & \multicolumn{2}{c|}{16} & \multicolumn{2}{c|}{09} \\
\hline Realização & 52 & $89,6 \%$ & 10 & $66,5 \%$ & 01 & $11 \%$ \\
\hline Não-realizadas & 06 & $10,4 \%$ & 06 & $33,5 \%$ & 08 & $89 \%$ \\
\hline
\end{tabular}


Para ilustrar as análises realizadas, apresentamos alguns exemplos das análises acústicas realizadas nas quais verificamos contextos em que os locutores realizaram as liaisons e outros em que elas não foram realizadas.

Por exemplo, a Figura 1 mostra a realização de uma liaison obrigatória. No trecho nous avons, produzido pelo falante nativo, observamos que a liaison suscitou um processo de ressilabação. Assim o falante produziu uma nova sílaba [za] com $123 \mathrm{~ms}$.

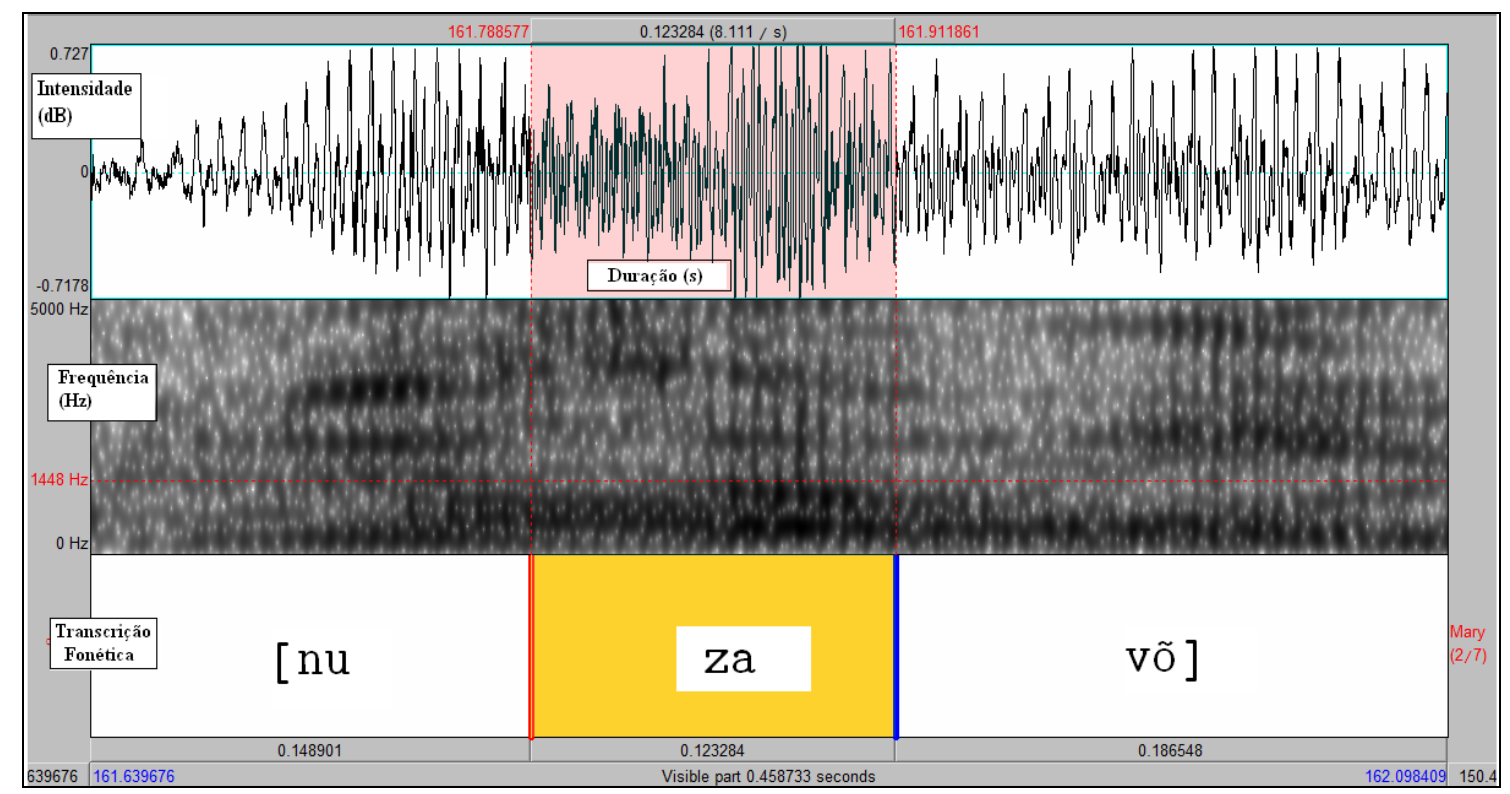

FIGURA 1. Forma de onda, espectrograma e camada de etiquetagem, na qual se vê a segmentação de nous avons.

Os dados analisados revelam ainda que mesmo os falantes nativos, em situação formal, ou seja, empregando o francês standard, podem não realizar todas as liaisons consideradas obrigatórias conforme a Gramática Normativa. Segundo a classificação de Delattre (1951 apud PAGLIANO e LAKS, 2005), aqui adotada como base para as análises: o verbo être, e suas flexões (est), quando impessoal e ocupando a posição de palavra 1, exige que se lance a liaison, como em c'est un, que deve sempre ser pronunciado [se. tã]. No entanto, observa-se, pela Figura 2, que o falante não realiza a liaison quando pronuncia a sentença c'est évidemment. A transcrição fonética ['se. e. vi. da. 'mõ] é exibida no espectrograma, no qual se pode ver a junção de dois [e], no lugar de uma liaison. 


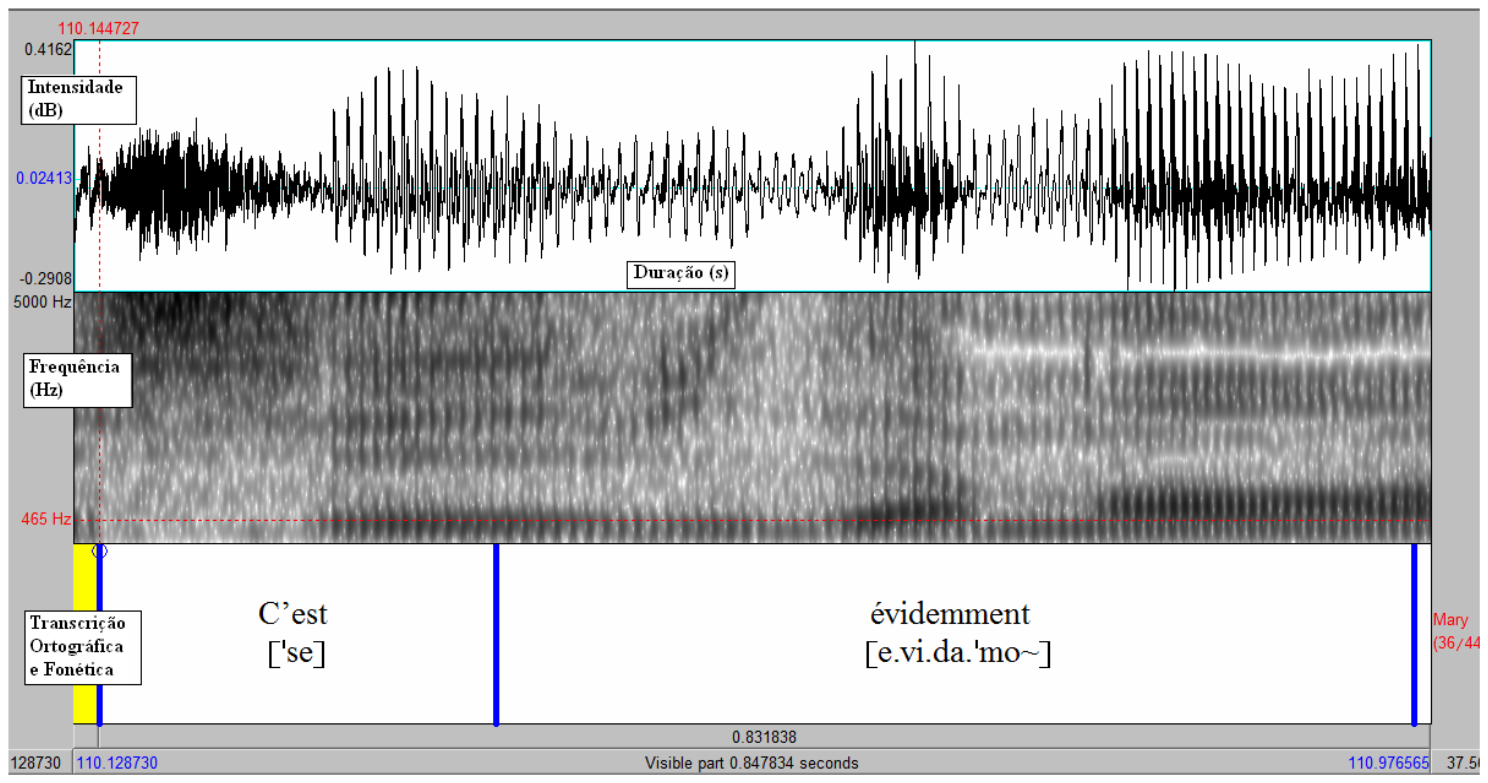

FIGURA 2. Forma de onda, espectrograma e camada de etiquetagem de c'est évidemment, pronunciado ['se. e. vi. da. 'mõ]

As liaisons facultativas podem ou não ser realizadas. Analisando os contextos favorecedores de liaisons facultativas, observamos as duas possibilidades. Na Figura 3, pode ser observada a realização de uma liaison facultativa. A opção de realizá-la desencadeou o processo de ressilabação, ou seja, uma nova sílaba [ta] com 109ms.

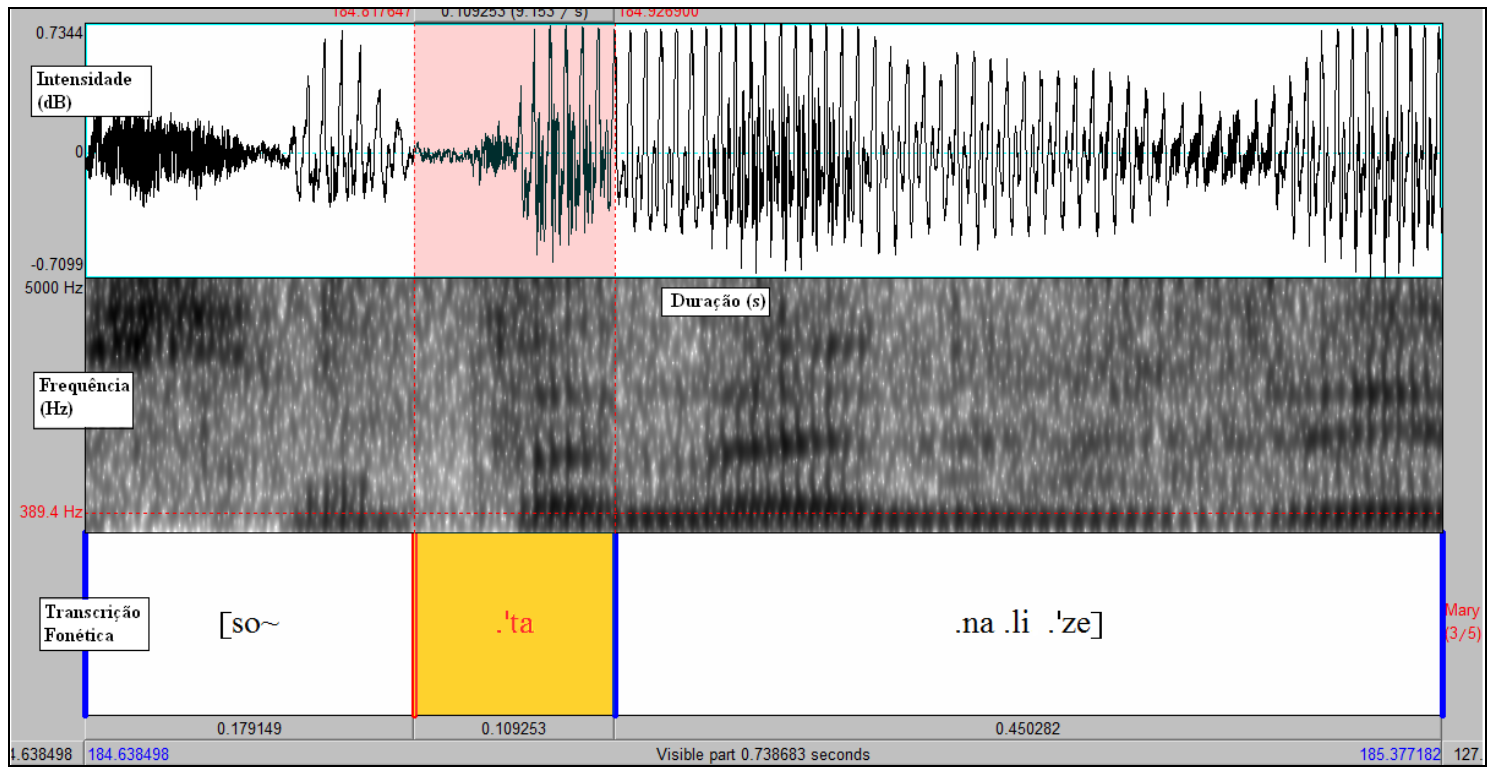

FIGURA 3. Forma de onda, espectrograma e camada de etiquetagem de sont analysés.

Agora, na Figura 4, tem-se um outro caso de liaison facultativa realizada. Essa realização deveria fazer surgir uma consoante latente $[\mathrm{z}]$, uma vez que corresponde ao trecho spectateurs attendus. No entanto, o falante nativo, nesse caso, fez uma liaison fazendo surgir o segmento fonético [R] que ocupa a coda da última sílaba pronunciada da palavra 1. A transcrição fonética do sintagma spectateurs attendus foi registrada como ['spek . ta . 'tœR. a. 'tõ . dy], demonstrando que o locutor 
apenas encadeou a pronúncia da palavra $1+$ palavra 2 , ignorando o [s] latente da palavra 1, a marca de plural.

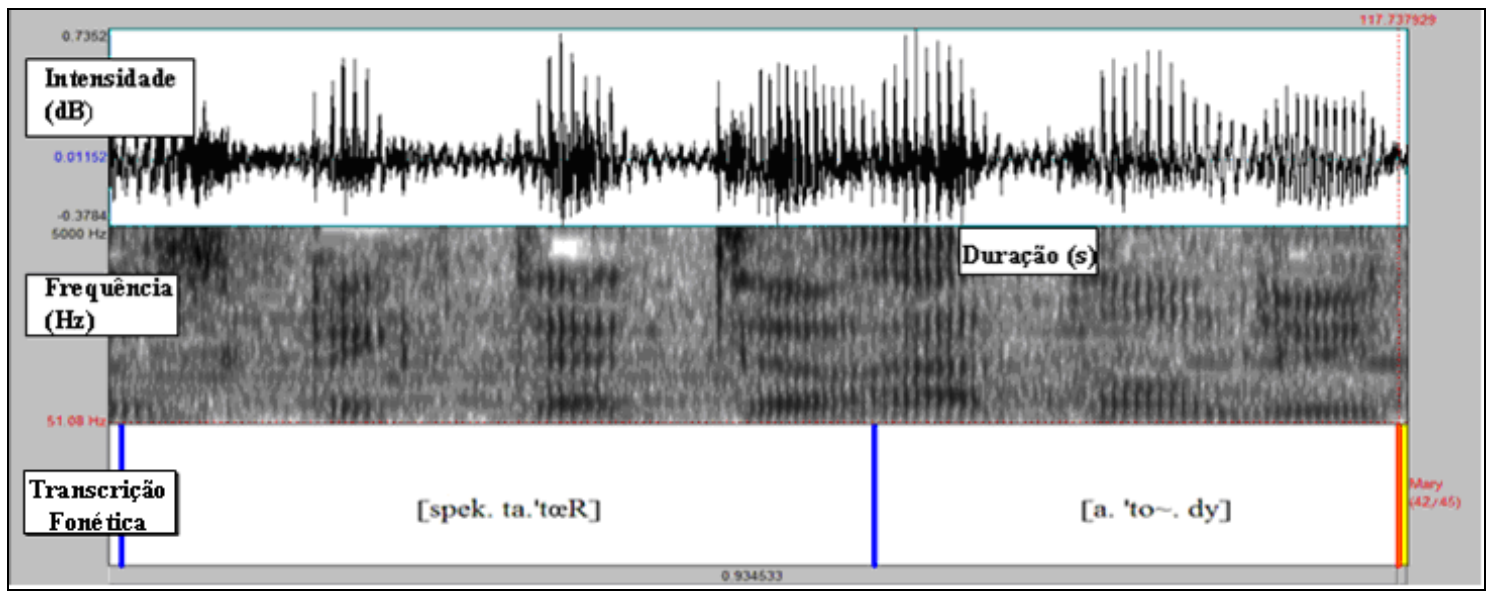

FIGURA 4. Forma de onda, espectrograma e camada de etiquetagem de spectateurs attendus. $\mathrm{O}$ falante nativo não realizou a liaison $\mathrm{em}[\mathrm{z}]$, mas em [R].

Com relação às liaisons proibidas, segundo a classificação adotada, o contexto "verbo + verbo no infinitivo" é considerado um caso de liaison proibida (ver Quadro 2). Observando a realização apresentada na Figura 5, nota-se que o falante produz o trecho da sentença peuvent être, sem fazer liaison, o que seria a pronuncia esperada. A transcrição fonética do sintagma produzido pelo falante nativo é ['pø v. 'etR].

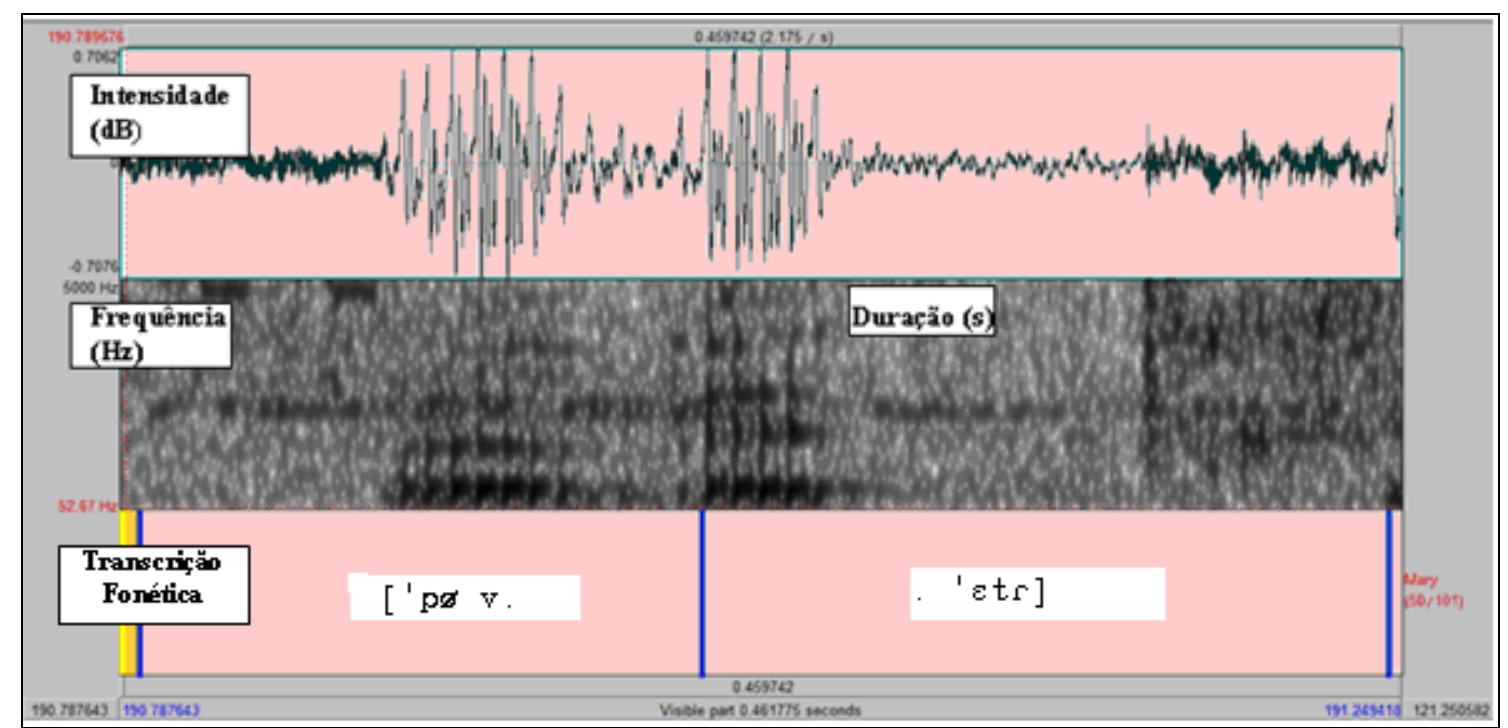

FIGURA 5. Forma de onda, espectrograma e camada de etiquetagem de peuvent être.

Porém, na Figura 6, que corresponde à produção do trecho doit être, observa-se que o falante realizou a liaison considerada proibida (verbo + verbo no infinitivo) e por consequência houve um processo de ressilabação ['dwa. 'tetR]. Mesmo que essa realização não nos pareça estranha, ou seja, não cause estranhamento aos ouvidos habituados ao francês, não se pode deixar de considerar que se trata de uma realização proibida, segundo a classificação exposta no Quadro 2. A nova sílaba ['tetR], fruto dessa liaison, tem $265 \mathrm{~ms}$. 


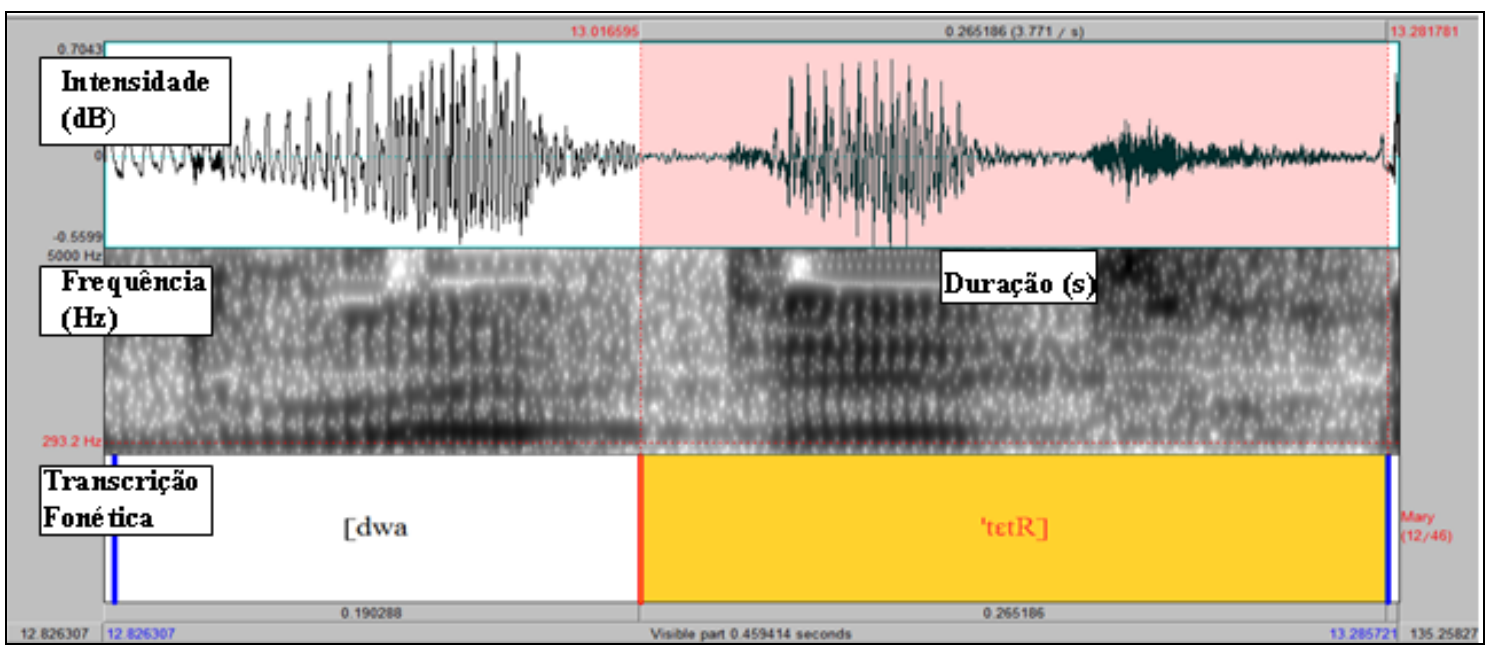

FIGURA 6. Forma de onda, espectrograma e camada de etiquetagem de doit être.

\subsection{Aprendizes de FLE}

Agora, vamos olhar os dados relativos aos aprendizes de FLE, analisando em separado os falantes do nível debutante (A), intermediários (B, C) e avançado (D). Esses resultados estão dispostos na Tabela 2 e aqueles referentes aos tipos de liaisons na Tabela 3.

TABELA 2. Resultados separados por texto e por nível do aprendiz de FLE das liaisons realizadas

\begin{tabular}{|l|c|c|c|c|c|c|c|c|}
\hline \multicolumn{1}{|c|}{ Liaison } & \multicolumn{4}{|c|}{ Texto 1 } & \multicolumn{4}{c|}{ Texto 2 } \\
\hline & $\mathrm{A}$ & $\mathrm{B}$ & $\mathrm{C}$ & $\mathrm{D}$ & $\mathrm{A}$ & $\mathrm{B}$ & $\mathrm{C}$ & $\mathrm{D}$ \\
\hline obrigatória & $4 / 17$ & $4 / 17$ & $2 / 17$ & $12 / 17$ & $22 / 41$ & $6 / 41$ & $14 / 41$ & $22 / 41$ \\
\hline facultativa & $0 / 5$ & $1 / 5$ & $0 / 5$ & $4 / 5$ & $1 / 11$ & $0 / 11$ & $0 / 11$ & $6 / 11$ \\
\hline proibida & $0 / 1$ & $0 / 1$ & $0 / 1$ & $1 / 1$ & $2 / 8$ & $0 / 8$ & $0 / 8$ & $6 / 8$ \\
\hline
\end{tabular}

Um caso a remarcar é que, em grande parte das situações em que deveria haver liaison, seja obrigatória ou facultativa, aparece uma pausa de silêncio (que vai de 10 a 500ms), o que pode indicar que o sujeito faz uma reflexão sobre o uso ou não da liaison. Para os aprendizes A, B e C, a pausa leva a não realização da liaison. Porém, para o aprendiz D, a pausa antecede a sílaba que apresenta o fenômeno da liaison, conforme se pode observar na Figura 9 mais adiante.

Observando os dados apresentados na Tabela 3, constata-se que os aprendizes de FLE mostram um comportamento bastante distinto dos nativos de francês. As liaisons obrigatórias são empregadas com maior preferência pelos aprendizes do nível mais avançado (D) $(58,62 \%)$. Esses dados mostram um comportamento diferente dos aprendizes em relação aos nativos que realizaram $89,6 \%$ das possibilidades de liaisons obrigatórias. Em seguida, aparecem os resultados relativos ao nível debutante (A), que mostrou 44,82\% de realização das liaisons obrigatórias. No nível intermediário (B e C), os dados apresentaram as menores porcentagens de uso da liaison obrigatória $(17,42 \% \mathrm{e}$ $27,58 \%$, respectivamente). 
TABELA 3. Liaisons realizadas por falantes aprendizes de FLE

\begin{tabular}{|l|c|c|c|}
\hline & $\begin{array}{c}\text { Liaison } \\
\text { Obrigatória }\end{array}$ & $\begin{array}{c}\text { Liaison } \\
\text { Facultativa }\end{array}$ & $\begin{array}{c}\text { Liaison } \\
\text { Proibida }\end{array}$ \\
\hline A & $26(44,82 \%)$ & $01(6,25 \%)$ & $02(22,22 \%)$ \\
\hline B & $10(17,24 \%)$ & $01(6,25 \%)$ & 0 \\
\hline C & $16(27,58 \%)$ & 0 & 0 \\
\hline D & $34(58,62 \%)$ & $10(62,5 \%)$ & $07(77,78 \%)$ \\
\hline
\end{tabular}

Ainda, pela Tabela 3, pode-se observar que, como os falantes nativos, no nível mais avançado (D), vemos um maior percentual de uso da liaison em contextos em que ela é facultativa $(62,5 \%)$, próximo do apresentado pelos falantes nativos $(66,5 \%)$. No entanto, nos níveis debutante (A) e intermediário (B e C), ocorreram entre $0 \%$ e $6 \%$ de liaisons em contextos facultativos.

Já, nas liaisons proibidas, o comportamento do nível mais avançado (D) é totalmente diferente dos falantes nativos, apresentando agora uma alta prevalência de realização de liaisons proibidas (77,78\% contra $11 \%$ de realização pelos falantes nativos). Os demais aprendizes apresentam o comportamento esperado para os falantes nativos, isto é, evitam a realização de liaisons proibidas, conforme se pode ver pela Tabela 3.

Passando agora a ilustrar algumas das análises acústicas realizadas sobre os dados dos aprendizes de FLE, verifica-se, pela Figura 7, que o locutor não teve problemas para realizar a liaison obrigatória na produção do trecho les autorités, conforme se pode confirmar pelo processo de ressilabação apresentado nessa figura. A nova sílaba [zo] tem $162 \mathrm{~ms}$.

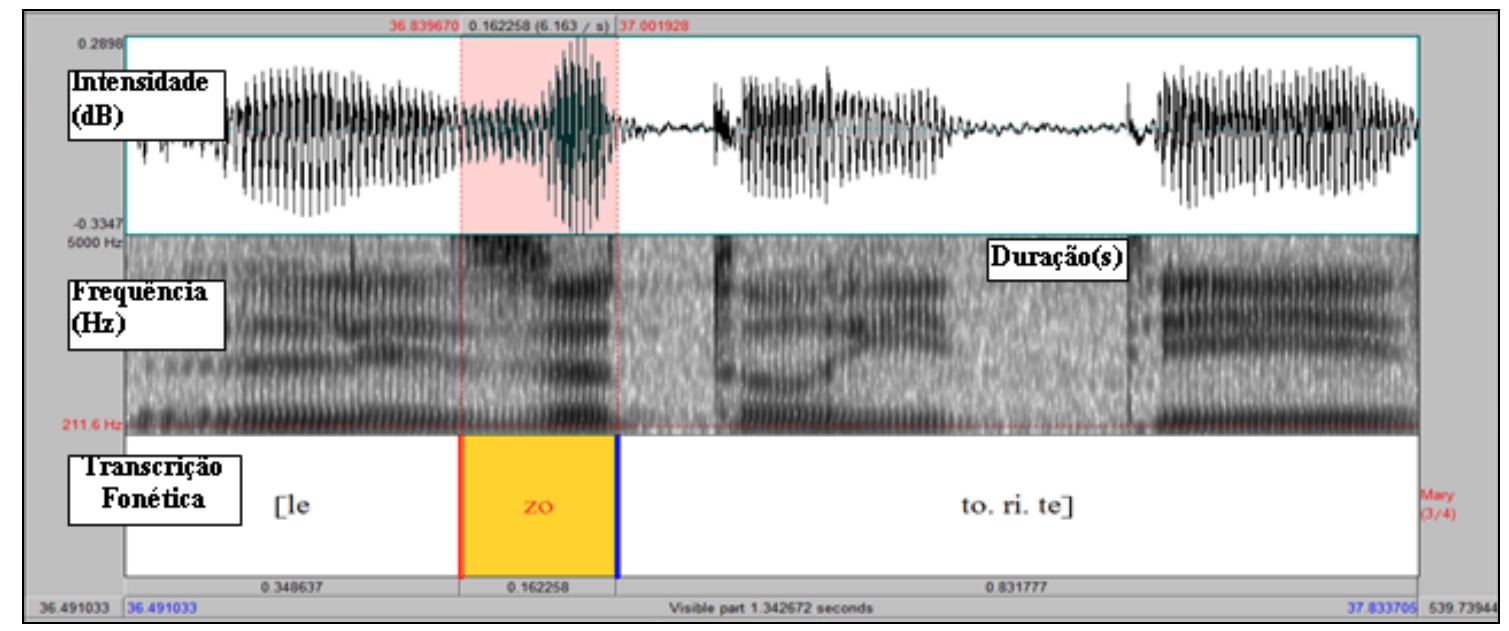

FIGURA 7. Forma de onda, espectrograma e a camada de etiquetagem de les autorités.

Entretanto, na Figura 8, vê-se outra situação: o aprendiz não realizou a liaison obrigatória entre o determinante les e o substantivo idées. Nesse caso, constatou-se uma pausa de $520 \mathrm{~ms}$ (muito extensa) entre a palavra 1 e a palavra 2 . Um dado a se ressaltar nas análises dos aprendizes de FLE é a frequência de pausas entre as palavras 1 e 2 nos casos de liaisons obrigatórias. 


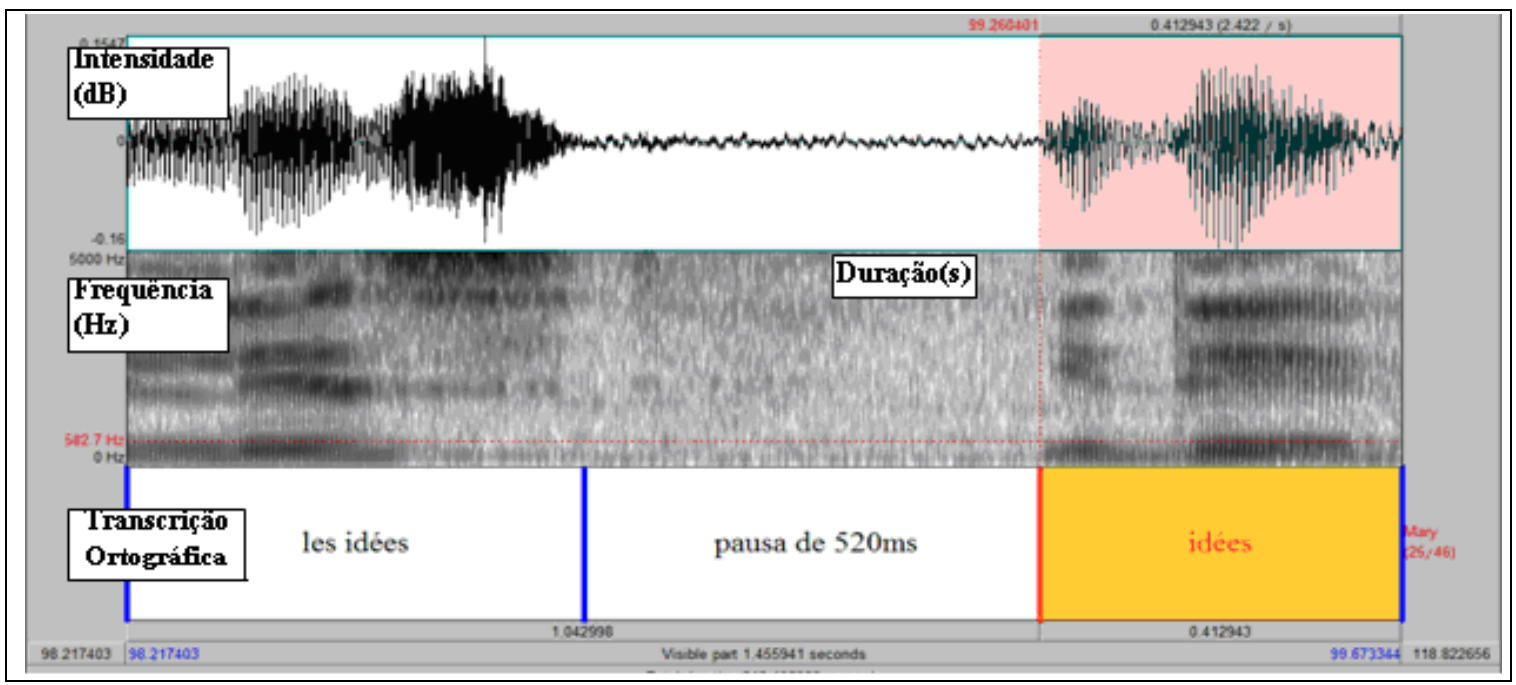

FIGURA 8. Forma de onda, espectrograma e camada de etiquetagem de les idées.

As liaisons facultativas são consideradas variáveis. Pela Figura 9, por exemplo, vê-se que o locutor realizou a liaison facultativa em tout est e, consequentemente, observa-se um processo de ressilabação. Observando a nova sílaba de $341 \mathrm{~ms}$ no espectrograma da Figura 9, verifica-se que existe uma pausa antes dessa sílaba, o que mostra uma hesitação a respeito da realização desse tipo de liaison.

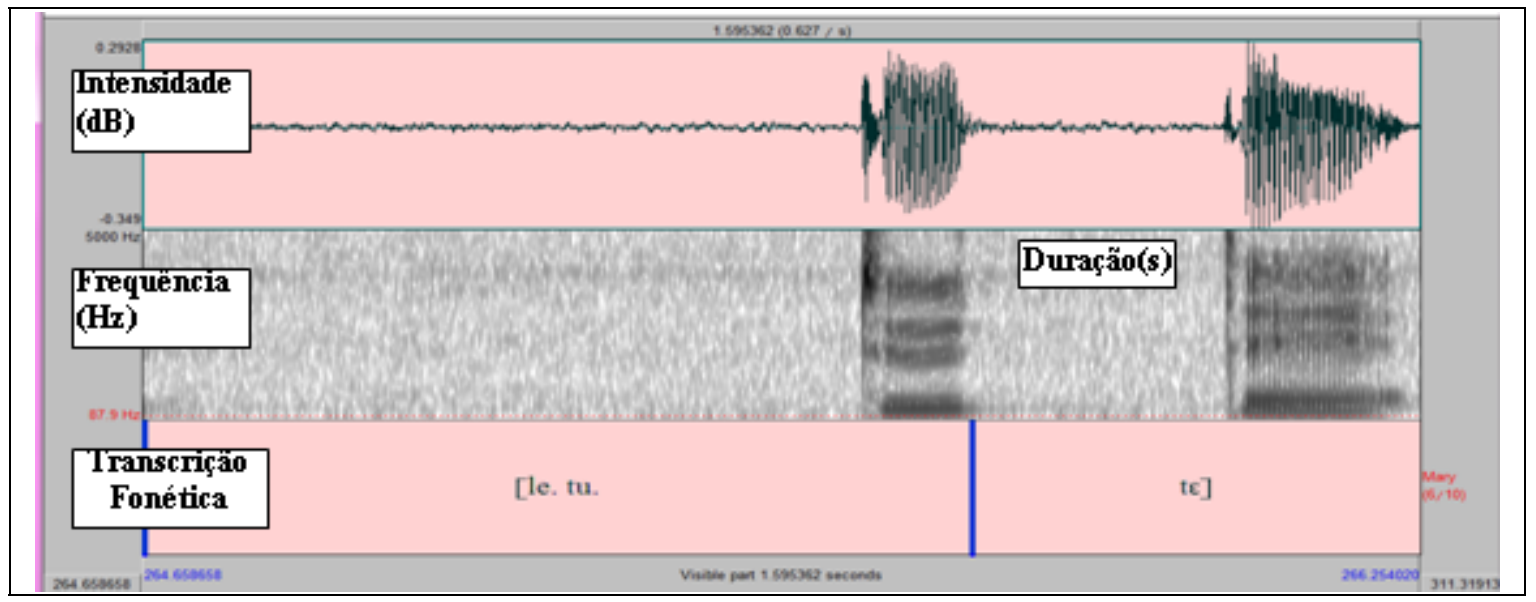

FIGURA 9. Forma de onda, espectrograma e camada de etiquetagem de le tout est.

Mas, nem todas as liaisons facultativas foram realizadas pelos aprendizes. Na Figura 10, por exemplo, o locutor fez uma pausa de $86 \mathrm{~ms}$ entre a palavra 1 (est) e a palavra $2(\grave{a})$; e, portanto, não realizou a liaison facultativa. 


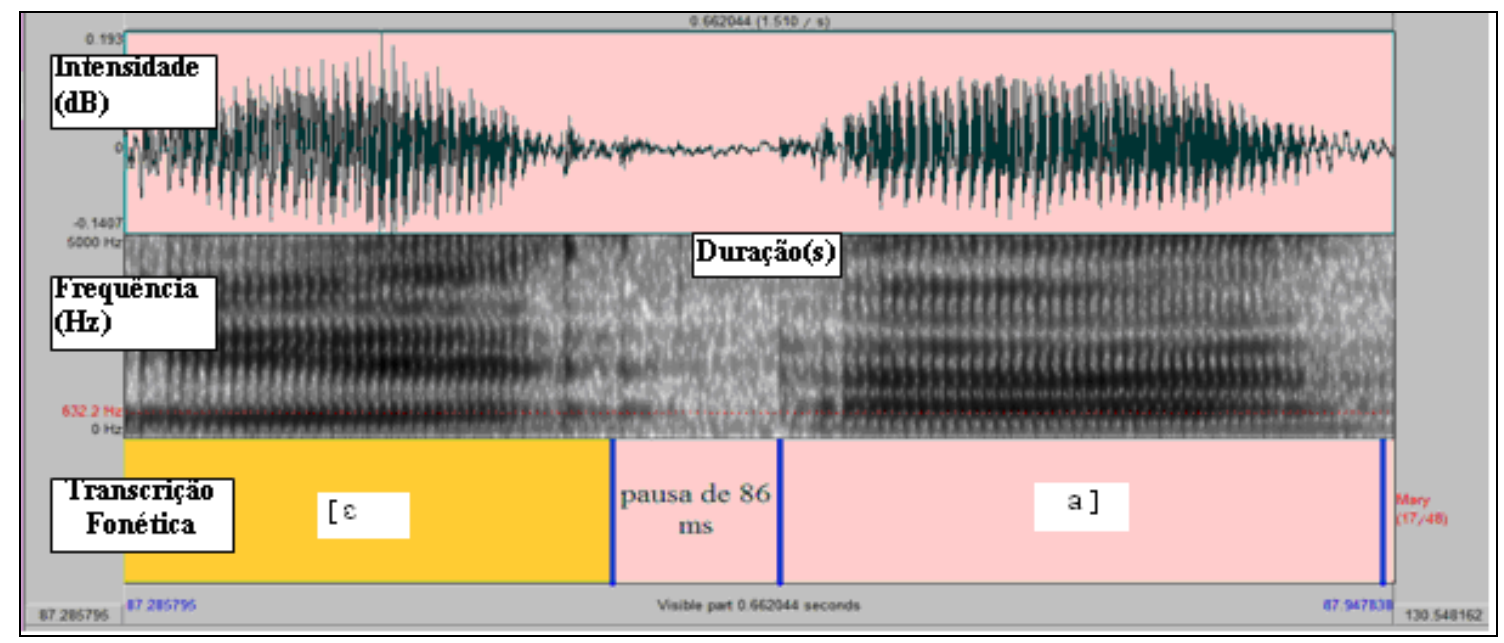

FIGURA 10. Forma de onda, espectrograma e camada de etiquetagem de est à.

As Figuras 11 e 12 ilustram contextos em que a liaison é proibida. Na Figura 11, observa-se que o locutor também fez uma pausa de 134ms entre a palavra 1 (peuvent) e a palavra 2 (alors) e, portanto, não realizou a liaison proibida.

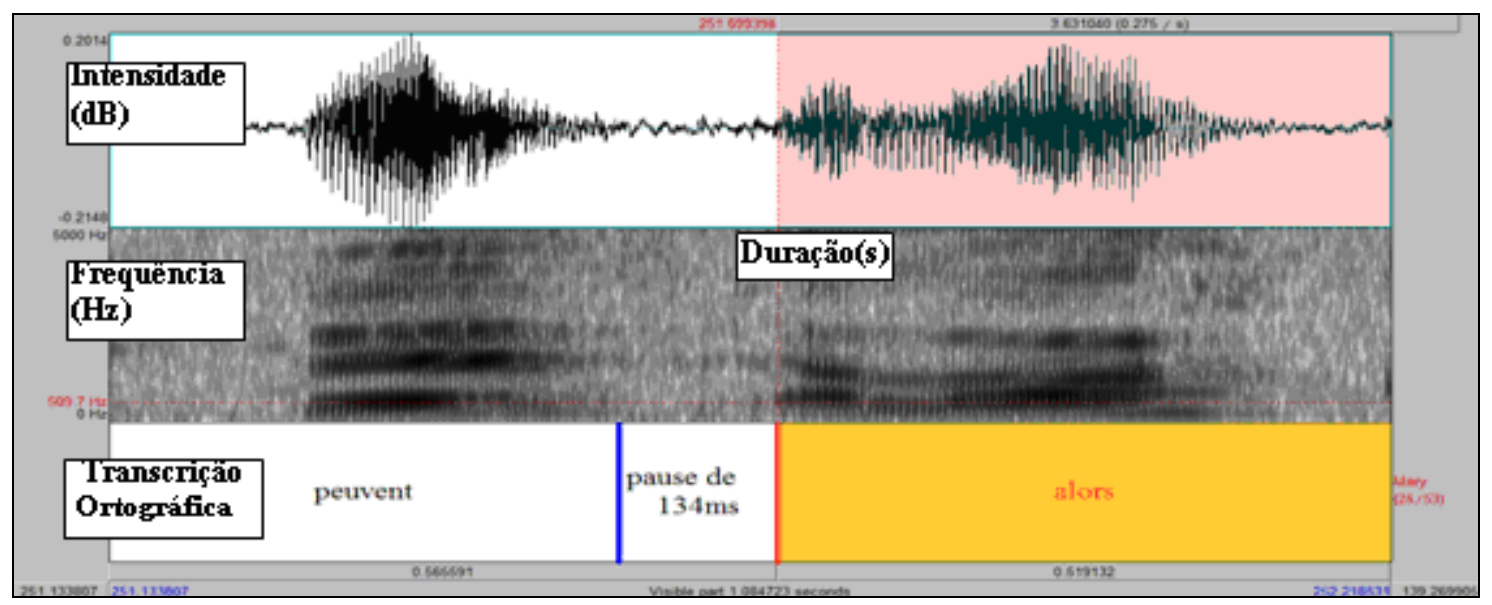

FIGURA 11. Forma de onda, espectrograma e camada de etiquetagem de peuvent alors.

Na Figura 12, ao contrário, vê-se que o locutor pronunciou gent ont, realizando uma liaison em contexto em que ela seria proibida, ocorrendo, por conseqüência, um processo de ressilabação. Pode-se deduzir, no entanto, que o locutor também refletiu sobre a pronúncia, uma vez que se vê um alongamento da sílaba precedente. 


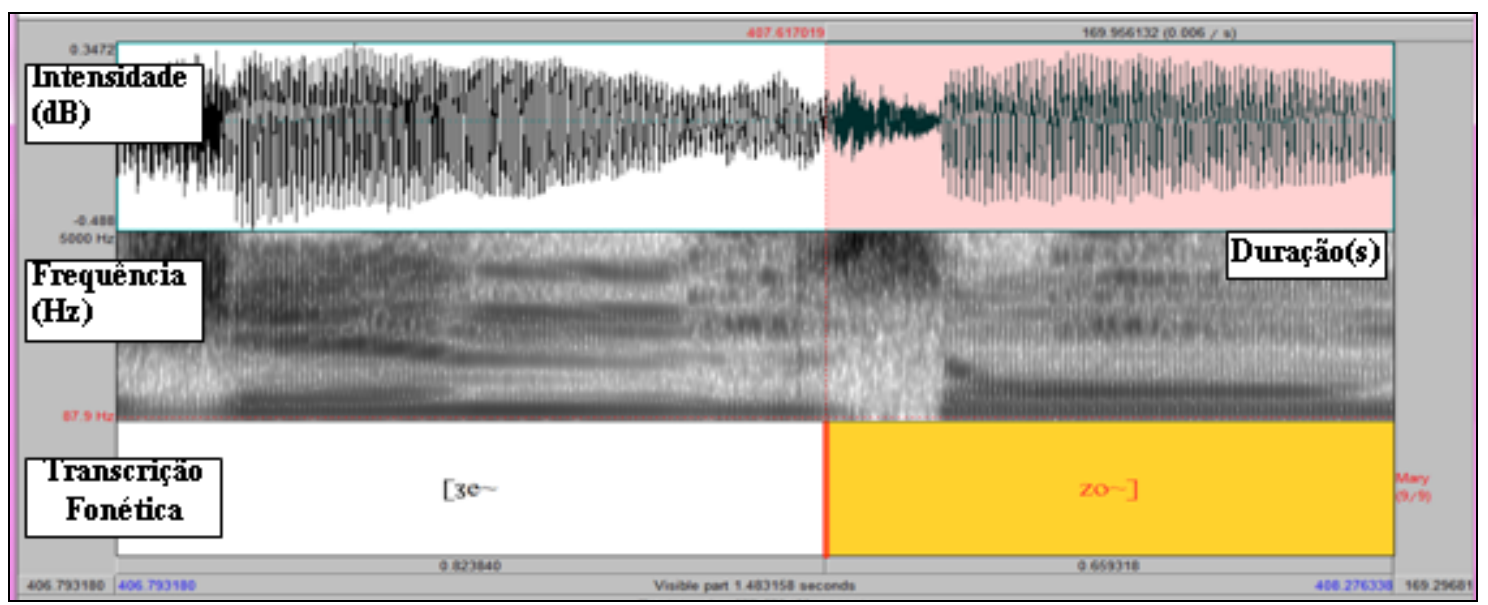

FIGURA 12. Forma de onda, espectrograma e camada de etiquetagem de gens ont.

\subsection{A falsa liaison}

A análise dos dados nos levou ainda a outros tipos de liaisons. A literatura considera que os locutores, às vezes, inserem uma consoante epentética [ $\mathrm{n}],[\mathrm{t}]$ ou $[\mathrm{z}$ ] entre duas palavras, mesmo que essa consoante não corresponda à consoante latente esperada para a realização da liaison. Denomina-se falsa liaison a esse fenômeno.

Então, além das liaisons obrigatórias, facultativas e proibidas, considerou-se um quinto tipo de fenômeno fonológico: a falsa liaison. Chevrot et al. (2007) afirmam que a aparição, às vezes obrigatória, de um [t], por exemplo, fruto de uma liaison, pode influenciar outras pronúncias. Segundo esses autores, a utilização frequente de enunciados do tipo: il est allé ou on est arrivé, na terceira pessoa do singular, pode levar à seguinte pronúncia na primeira pessoa do singular: [ $\int \mathrm{u}$ 'ta le] para je suis allé. $\mathrm{O}[\mathrm{t}]$ latente em alguns verbos deve estar ligado a uma vogal ou a um $\mathrm{h}$ mudo para que se realize uma nova sílaba, processo que não tem razão de existir no exemplo apresentado, uma vez que se trata de verbo conjugado na primeira pessoa. Seria a influência da exposição à forma na terceira pessoa do singular, um caso semelhante ao que ocorre na produção de crianças nativas.

Mas, ampliando um pouco o espectro e considerando falsa liaison as realizações que não tinham motivação, foram destacadas todas as produções de consoantes e vogais que promoveram liaison. Verificou-se que a prática de realizar liaisons pode ser favorecida por influência do português, como nota-se em produções de palavras em francês, cuja ortografia é próxima do português. Um exemplo é a palavra "style" normalmente pronunciada [es "tile] ou [is "tile], aos moldes da palavra "estilo" do português. (NUNES, 2008).

Na Figura 13, tem-se a produção do trecho: ces spectacles. A palavra 2 começa por consoante e, dessa maneira, não haveria motivo para a realização de uma liaison. Acredita-se, no entanto, que, por influência do português (a palavra spectacle é muito próxima da palavra "espetáculo" do português) e pela dificuldade de realizar um onset complexo do tipo sp, o locutor insere uma vogal epentética no início dessa palavra, transformando o onset complexo spe em is.pe, realizando então uma falsa liaison com o 
pronome que antecede o nome spectacles. Por consequência, apresenta um processo de ressilabação.

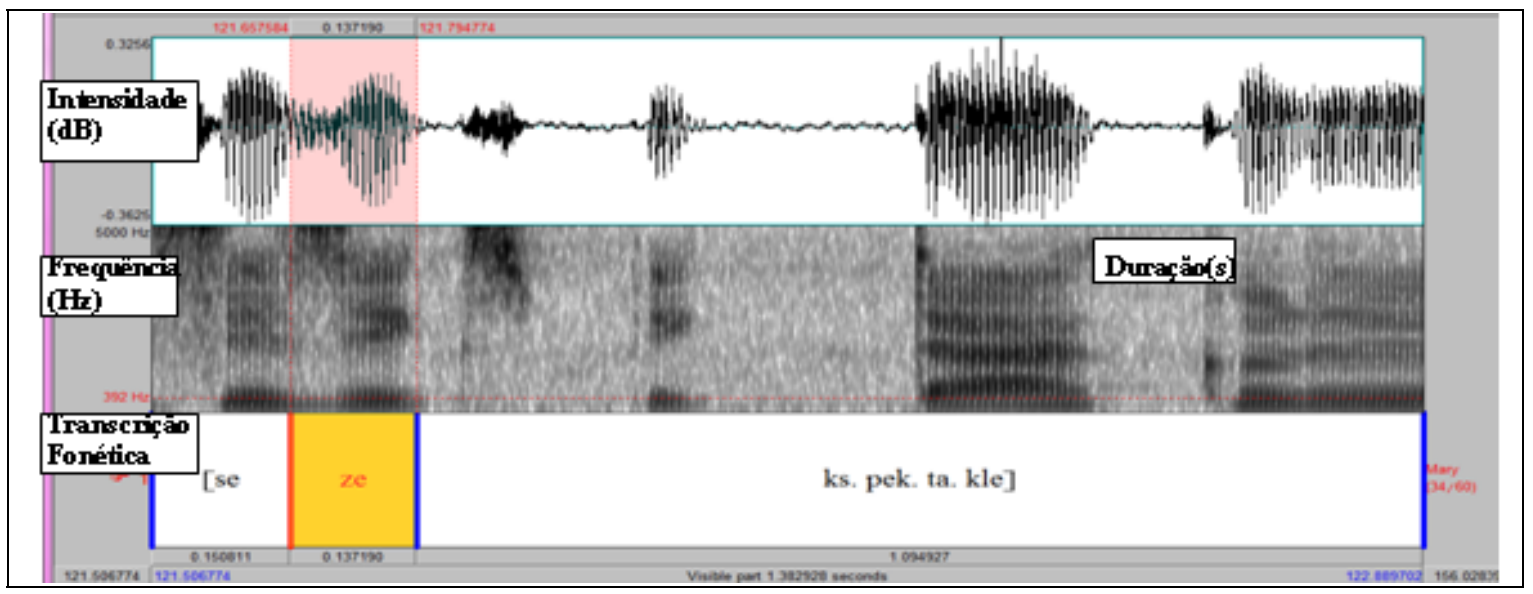

FIGURA 13. Forma de onda, espectrograma e camada de etiquetagem de ces spectacles.

A Figura 14 exibe outro tipo de falsa liaison. Na produção de c'est ici, o locutor realizou a liaison com um [z] no lugar de um [t], influenciado talvez pela consoante $\mathrm{s}$ presente na forma verbal.

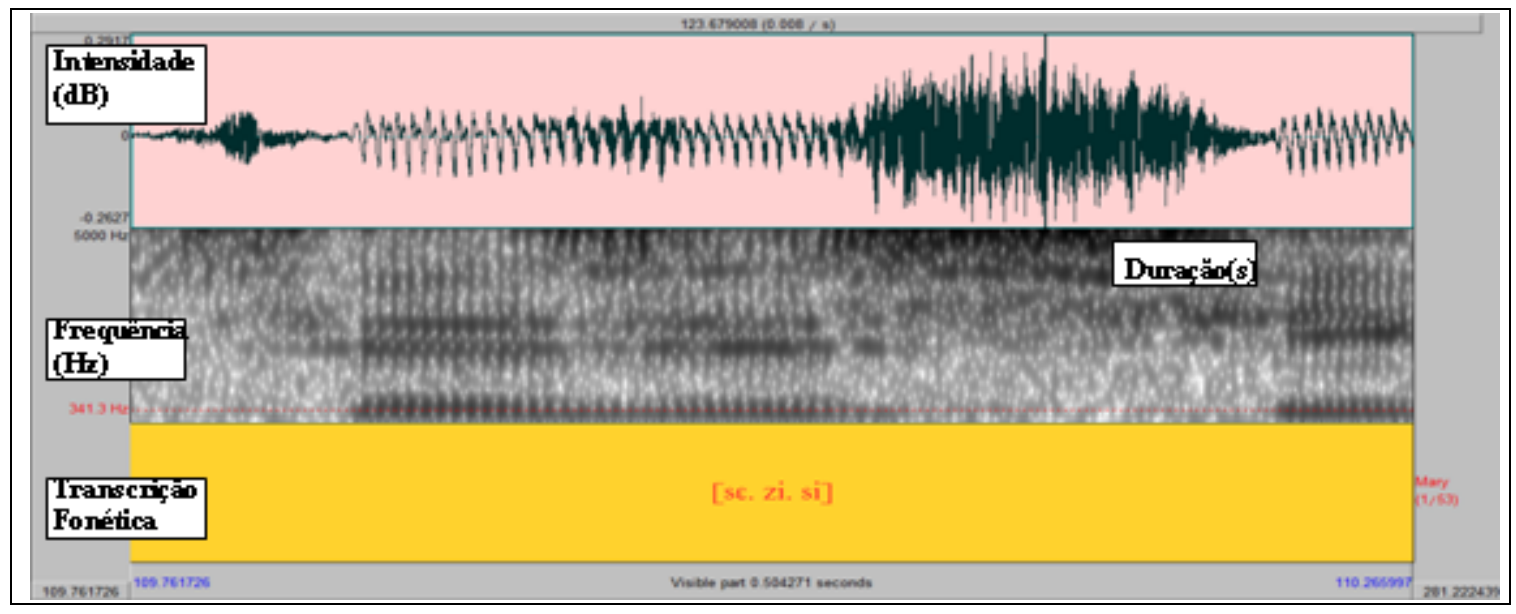

FIGURA 14. Forma de onda, espectrograma e camada de etiquetagem de c'est ici.

\section{CONCLUSÕES}

Vamos então tentar responder as questões levantadas para este estudo. Primeiramente, se os jornalistas nativos do francês e os aprendizes de FLE realizam todas as liaisons obrigatórias. Apesar de os nativos apresentarem 89,6\% de realizações das liaisons obrigatórias, em $10,4 \%$ elas não ocorreram. Já os aprendizes foram bem mais econômicos no uso de liaisons obrigatórias, variando de 17,24\% a 58,62\%.

Em segundo lugar, queríamos saber como os locutores realizam as liaisons facultativas. Os nativos mostraram uma preferência para realizarem as facultativas $(66,50 \%)$. Já os aprendizes de FLE dos níveis intermediário (B e C) e debutante (A) optaram por praticamente não as realizarem (variando de $0 \%$ a $6,5 \%$ ). No entanto, no nível avançado (C), houve $62,5 \%$ de liaisons facultativas. 
Agora, quanto às proibidas, os nativos produziram apenas uma liaison proibida, e os aprendizes dos níveis $\mathrm{B}$ e $\mathrm{C}$ também não as realizaram. Já o aprendiz do nível mais avançado (D) apresentou uma grande ocorrência de liaisons proibidas (77,78\%). Justificamos tal produção como a possibilidade de hipercorreção, dessa forma, demonstrando uma consciência maior de uso desse tipo de fenômeno na língua francesa.

Finalmente, pudemos observar a presença de falsas liaisons, influenciadas pela língua materna dos aprendizes, gerando fenômenos como apagamento e ressilabação próprios das liaisons obrigatórias.

Os resultados aqui apresentados parecem também mostrar que dois fatores podem estar condicionando a realização das liaisons obrigatórias: (i) a ordem de apresentação dos textos, parecendo que, na leitura do segundo texto, o aprendiz está mais tranqüilo (menos nervoso do que no momento da primeira leitura) e (ii) a complexidade/conhecimento do conteúdo dos textos.

\section{REFERÊNCIAS}

CHABANAL, D.. Un aspect de l'acquisition du français oral : la variation sociophon'etique chez l'enfant francophone. Thèse, Université Montpellier 3, 2003.

CHEVROT, J. P. CHABANAL, D. \& DUGUA, C. Pour un modèle de l'acquisition des liaisons basé sur l'usage : trois études de cas, Journal of French Language Studies. Cambridge University Press, 2007.

CHEVROT, J. P. DUGUA, C., FAYOL, M. Liaison et formation des mots en français: un scénario déveleppemental. Revue Langages. LIDILEM, Université Stendhal \& LAPSCO, Université Blaise Pascal - CNRS. France, 2005.

DELATTRE, P. Principes de phonetique française à lusage des étudiants angloamericains. Mid dlebury, VT : Middlebury College Press, 1951.

DUGUA, C. \& CHABANAL, D. Acquisition de la liaison chez l'enfant francophone : formes lexicales des Mots 2. Artigo apresentado na XVIes Journées d'Études sur la Parole (JEP). Manoir de la Vicomté - Dinard - França, 2006.

HOWARD M. "L’acquisition de la liaison en français langue seconde - Une analyse quantitative d'apprenants avancés en milieu guidé et en milieu naturel". Corela, Numéros spéciaux, Colloque AFLS, 2005.

LAKS B. L'oral et la variation in La prononciation du français dans sa variation J. Durand, B. Laks et Ch. Lyche La tribune internationale des langues vivantes, 2003.

LAKS, B. La liaison et l'illusion. Langages, Paris: Larousse, 2005.

LÉON, P. Prononciation du français standart: Aide-mémoire d'orthoepie. Paris : Ddier, 1966. 
MALMBERG, B. La phonetique. Paris : Presses Universitaires de France, 1976.

MOUGEON, R., NADASDI, T. e REHNER H. État de la recherche sur l'appropriation de la variation par les apprenants avancés du FL2 ou FLE. In Acquisition et Interaction en Langue Étrangère: L'Acquisition de la variation par les apprenants du français langue second, 2003. Disponível em: http://aile.revues.org/document847.html. Acessado em 20 de junho de 2009.

NUNES, V O fenômeno da "liaison" na leitura em voz alta: o caso de aprendizes de Francês Língua Estrangeira. VIII Encontro do CELSUL, Porto Alegre: EDUCAT, outubro, 2008.

PAGLIANO, C. \& LAKS, B. Problématiques de la liaison dans l'analyse d'un corpus de français oral actuel. Inconnu. Lyon, 2005.

PIERRET, J M. Phonétique historique Du français et notions de phonétique général. Nouvelle édition, Louvain-la Neuve, Peeters, 1994.

ROSSI. A. Análise auditiva e acústica do fenômeno da ligação do francês com consoantes sonoras realizado por estudantes brasileiros. Dissertação UFSC, 1998.

STRIDFELD, M. La perception du français oral par des apprenants suédois. Umeå: Institutionen för moderna språk, Umeå universitet, 2005.

THOMAS, A. La liaison et son enseignement : des modèles orthoépiques à la réalité linquistique. Canadian Modern Language Review 54 n4 1998. P. 543-52.

WIOLAND, F e PAGEL, D. Le français parlé. Pratique de la prononciation du français. Florianópolis: Editora da UFSC, 1991.

PLOUZEAU, M. Laboratoire de Français Ancien. Disponível em: http://www.uottawa.ca/academic/arts/lfa/. Acessado em 27 de junho de 2009. 